\title{
Arrhythmias after the Fontan procedure
}

Nicholas S Peters, Jane Somerville

Department of Cardiac Medicine, National Heart and Lung Institute, London

N S Peters

Grown-up Congenital Heart Unit, Royal Brompton and National Heart and Lung Hospital, Chelsea, London J Somerville

Correspondence to Dr Jane Somerville, Grownup Congenital Heart Unit, Royal Brompton and National Heart Hospital, Sydney Street, London SW3 6NP

Accepted for publication 13 February 1992

\begin{abstract}
Objective-To study the determinants and outcome of arrhythmias after the Fontan type operation.

Design-Retrospective analysis of data in patients operated on between 1972 and 1986 (follow up 5-19 years (mean 12 years)).
\end{abstract}

Patients-All 60 patients undergoing a Fontan type procedure at the National Heart Hospital, London, during the study period (mean age (SD) $12 \cdot 3(6.8)$ years).

Results-Postoperative arrhythmias occurred in 34 patients $(57 \%)$, and 11 $(58 \%)$ of 19 early postoperative deaths (within seven days) were related to arrhythmias. Early arrhythmias occurred in $19 .(32 \%)$ patients of whom $11(58 \%)$ died. All patients with early atrial fibrillation and His bundle tachycardia died and only preoperative atrial fibrillation recurred early. There was a higher incidence of early arrhythmias, which were less well tolerated, in double inlet single ventricle patients $(9 / 19)$ than in those with tricuspid atresia $(8 / 37)$. There were no other preoperative determinants of early arrhythmias or deaths from early arrhythmia. Late (after seven days) arrhythmias occurred in 15 (37\% of hospital survivors). They had higher right atrial (RA) pressures both early and late after operation and had lower ventricular ejection fractions late after operation. Of those with atrial arrhythmias $86 \%$ had $R A$ obstruction and $57 \%$ had an RA thrombus or pulmonary embolism at presentation; this was also confirmed in two patients in whom late sudden deaths occurred. Atrial fibrillation early after reoperation for $R A$ obstruction was fatal. The actuarial arrhythmia free survival for hospital survivors was $60 \%$ at 10 years.

Conclusions-Early postoperative arrhythmias were poorly tolerated, particularly atrial fibrillation and His bundle tachycardia. Previous atrial fibrillation was a relative contraindication to this procedure. Late postoperative arrhythmias were associated with higher RA pressures measured both early and late after operation and worse late ventricular function. Late arrhythmias may be the first manifestation of RA obstruction, which must be sought. RA thrombus was common in patients with atrial arrhythmias and should be treated early with anticoagulants.

\section{(Br Heart J 1992;68:199-204)}

After Fontan and Baudet's description of a procedure for functional correction of tricuspid atresia in $1971,{ }^{1}$ variations of the technique have been used for many complex anomalies including double inlet ventricle. ${ }^{2}$ Arrhythmias cause problems in the natural history of these lesions but after creation of the Fontan circulation arrhythmias remain a risk and may be disastrous. This report focuses on the arrhythmias after the Fontan type operation and examines determinants of occurrence and outcome.

\section{Patients and Methods}

PATIENT SELECTION

Between 1972 and 198660 (31 male and 29 female) patients had a Fontan procedure, or a modification, at the National Heart Hospital London and all continued regular out patient attendance, providing at least five years of follow up in each case.

ASSESSMENT OF PATIENTS

Every patient had full preoperative clinical assessment including electrocardiography, echocardiography, cardiac catheterisation, and (since 1980) radionuclide ejection fraction assessment of the systemic ventricle. On completion of the Fontan procedure, right atrial pressure was measured before closure of the chest and continuously monitored for the first 24 hours through a central venous line, with continuous monitoring of cardiac rhythm during the operative and early postoperative period. During follow up, electrocardiography was carried out at six monthly clinic visits, with annual 24 hour Holter recordings, echocardiography, exercise testing, and radionuclide ejection fraction assessment. Invasive and other investigations were undertaken when clinically indicated.

In this study the early postoperative period was defined as the first seven days after operation. The occurrence of arrhythmias early and late (more than seven days) after the Fontan procedure was correlated with the following variables:

Preoperative-Underlying anatomical anomaly, previous shunt surgery, haemoglobin concentration, arrhythmias, ventricular function, left atrioventricular (AV) valve function, right atrial and pulmonary artery 
Table 1 Age at operation

\begin{tabular}{|c|c|}
\hline Age grousp & $\begin{array}{l}\text { No of } \\
\text { patients }\end{array}$ \\
\hline $\begin{array}{rr}11 & \text { months }-5 y \\
5 y & -10 y \\
10 y & -20 y \\
20 y & -28 y\end{array}$ & $\begin{array}{r}6 \\
18 \\
23 \\
13\end{array}$ \\
\hline
\end{tabular}

pressures, age at operation, and year of operation.

Postoperative-Immediate postoperative right atrial pressure, cardiac catheterisation pressure data, ventricular function, and age at onset of the arrhythmia.

\section{STATISTICAL ANALYSIS}

All group data are summarised as means (SD). Means were compared by unpaired Student's $t$ tests. Differences in proportions were analysed with the Fisher exact test. Statistical significance was defined as $\mathrm{p}<0.05$.

\section{Results}

PATIENT POPULATION

The anatomical anomalies for which the 60 patients were undergoing surgery were tricuspid atresia (TA, 37 patients), double inlet single ventricle (SV, 19 patients), congenitally corrected transposition of the great arteries (TGA) with absent venous atrioventricular (mitral) connection (two patients), double outlet right ventricle with straddling tricuspid valve, TGA and pulmonary valve stenosis (one patient), and pulmonary atresia with intact septum (one patient). Ages at operation ranged from 11 months to 28 years (mean $12.3(6 \cdot 8)$ years) (table 1). Previous shunt procedures had been performed in 44 patients (systemic to pulmonary shunt in 39 , Glenn anastomosis in nine, both in four), the first of which was between two and 27 (mean $11(4 \cdot 6)$ ) years before the Fontan procedure. Seven patients had a functional Glenn anastomosis after the Fontan procedure.

\section{SURGICAL PROCEDURE}

Figure 1 shows the chronological distribution of the 60 procedures during the period covered by our study. Various surgical techniques resembling the procedure first described by Fontan ${ }^{1}$ were used, some of which are now performed only infrequently at most centres. The right atrium was connected to the main pulmonary artery either by direct anastomosis (six patients) or through a conduit (35 patients, 32 with aortic homograft conduits and three with Dacron), to a mobilised subvalvar pulmonary outflow with a conduit incorporating the native pulmonary valve (five patients), and to the right ventricular infundibulum (14 patients).

POSTOPERATIVE FOLLOW UP

Postoperative follow up was five-19 (mean $12 \cdot 0(4 \cdot 2))$ years.

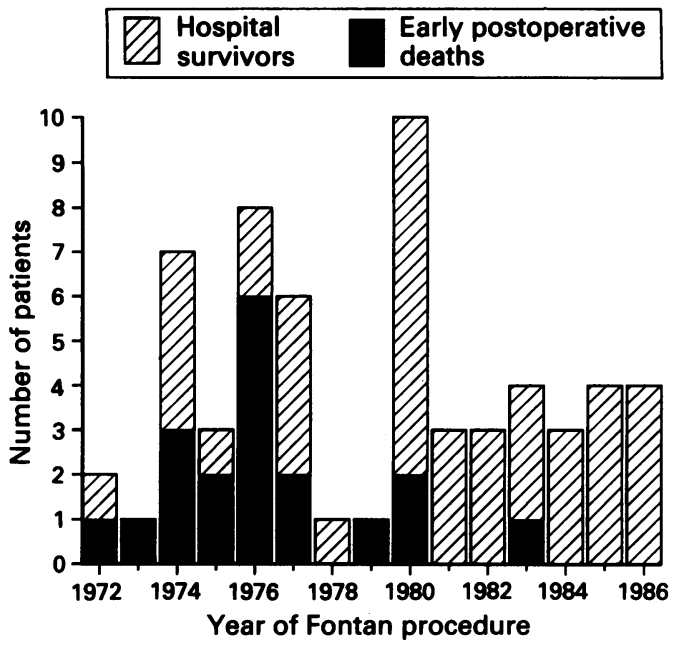

Figure 1 Distribution of Fontan procedures 1972-86, and hospital mortality.

Early deaths occurred in 19 patients (32\%); 16 of $29(55 \%)$ before 1980 and three of 31 $(10 \%)$ thereafter. This lessening of mortality was attributable to stricter patient selection and improved surgical technique.

Postoperative arrhythmias were documented in 34 patients $(57 \%)-19$ early and 15 late (four with both an early and a separate late presentation and nine within 24 hours after reoperation).

Eleven (58\%) of the 19 early deaths in hospital throughout the 15 year study period were directly associated with the onset of an arrhythmia.

\section{EARLY ARRHYTHMIAS}

Table 2 summarises the arrhythmias found and their outcome in the early postoperative period; 19 patients $(32 \%)$ had early arrhythmias and of these $11(58 \%)$ died in this period. Atrial fibrillation (five patients) and $\mathrm{His}$ bundle tachycardia (two patients) were always fatal. Four of the patients had an arrhythmia documented before the Fontan procedure (atrial fibrillation in one, reentrant supraventricular tachycardia in two, and an accelerated atrioventricular junctional rhythm in one), but only atrial fibrillation recurred in the early postoperative period, causing a rapid and uncontrollable ventricular response rate that led to death. The incidence of early arrhythmias was higher in SV $(9 / 19(47 \%))$ than TA $(8 / 37$ $(22 \%))(p=0.048)$, although the types of rhythm disturbance were the same in both groups. Early arrhythmias in the SV group were less well tolerated; $37 \%$ of patients

Table 2 Early postoperative arrhythmias (19 patients)

\begin{tabular}{|c|c|c|c|c|c|c|c|c|c|c|c|c|c|c|c|c|c|c|}
\hline \multirow{4}{*}{$\begin{array}{l}\text { Anomaly } \\
\text { Age at } \\
\text { operation (yr) } \\
\text { Fatal }\end{array}$} & \multicolumn{18}{|c|}{ Rhythm } \\
\hline & \multicolumn{5}{|c|}{$N R(n=5)$} & \multicolumn{6}{|c|}{$A F(n=6)$} & \multicolumn{2}{|l|}{ AFlut $(n=3)$} & \multicolumn{2}{|c|}{$H B T(n=2)$} & \multicolumn{2}{|c|}{$V T(n=2)$} & $C H B(n=2)$ \\
\hline & Sv & TA & TA & SV & SV & SV & SV & TA & TA & SV & TA & DORV TA & PA & sv & TA & sv & SV & SV TA \\
\hline & $\begin{array}{r}21 \\
0\end{array}$ & $\begin{array}{r}25 \\
0\end{array}$ & $\begin{array}{l}8 \\
0\end{array}$ & $\begin{array}{l}10 \\
+\end{array}$ & $\begin{array}{l}11 \\
+\end{array}$ & $\begin{array}{l}1 \\
+\end{array}$ & $\begin{array}{c}22 \\
+\end{array}$ & $\begin{array}{l}15 \\
+\end{array}$ & $\begin{array}{l}1 \\
+\end{array}$ & $\begin{array}{l}3 \\
+\end{array}$ & $\begin{array}{l}17 \\
+\end{array}$ & $\begin{array}{r}18 \\
0\end{array}$ & $\begin{array}{r}12 \\
0\end{array}$ & $\begin{array}{c}14 \\
+\end{array}$ & $\begin{array}{l}6 \\
+\end{array}$ & $\begin{array}{r}21 \\
0\end{array}$ & $\begin{array}{l}15 \\
+\end{array}$ & $\begin{array}{rr}21 & 7 \\
0 & 0 \\
\end{array}$ \\
\hline
\end{tabular}

NR, nodal rhythm (rate < 130 beats/min); AF, atrial fibrillation; AFlut, atrial flutter; HBT, His bundle tachycardia; VT, ventricular tachycardia; CHB, complete heart block; SV, double inlet single ventricle; TA, tricuspid atresia; DORV, double outlet right ventricle; PA, pulmonary atresia with intact ventricular septum; + , death associated with arrhythmia; 0 , survivor. 
Table 3 Late postoperative arrhythmias (15 patients)

\begin{tabular}{|c|c|c|c|c|c|c|c|c|c|c|c|c|c|c|c|c|}
\hline \multirow[b]{3}{*}{$\begin{array}{l}\text { Anomaly } \\
\text { Age at operation (yr) } \\
\text { Age at arrhythmia (yr) } \\
\text { RA-PA obstruction }\end{array}$} & \multicolumn{16}{|c|}{ Rhythm } \\
\hline & \multicolumn{3}{|c|}{$N R(n=3)$} & \multicolumn{3}{|c|}{$A F(n=3)$} & \multicolumn{4}{|c|}{ AFlut $(n=4)$} & \multicolumn{3}{|c|}{$S V T(n=3)$} & \multicolumn{2}{|c|}{$V T(n=2)$} & \multirow{2}{*}{$\begin{array}{l}\text { New CHB } \\
(n=1)\end{array}$} \\
\hline & $\begin{array}{l}\text { TA } \\
8 \\
9 \\
0\end{array}$ & $\begin{array}{l}\text { SV } \\
24 \\
25 \\
0\end{array}$ & $\begin{array}{l}\text { TA } \\
18 \\
19 \\
0\end{array}$ & $\begin{array}{l}\text { SV } \\
20 \\
30 \\
+\end{array}$ & $\begin{array}{l}\text { SV } \\
14 \\
22 \\
+\end{array}$ & $\begin{array}{l}\text { TA } \\
11 \\
12 \\
0\end{array}$ & $\begin{array}{l}\text { TA } \\
5 \\
6 \\
+\end{array}$ & $\begin{array}{l}\text { TA } \\
12 \\
13 \\
+\end{array}$ & $\begin{array}{l}\text { SV } \\
23 \\
25 \\
+\end{array}$ & $\begin{array}{l}\text { TA } \\
7 \\
16 \\
+\end{array}$ & $\begin{array}{l}\text { TA } \\
11 \\
20 \\
0\end{array}$ & $\begin{array}{l}\text { TA } \\
12 \\
20 \\
0\end{array}$ & $\begin{array}{l}\text { PA } \\
12 \\
13 \\
0\end{array}$ & $\begin{array}{l}\text { TA } \\
12 \\
19 \\
+\end{array}$ & $\begin{array}{l}\text { SV } \\
21 \\
22 \\
0\end{array}$ & \\
\hline
\end{tabular}

Footnotes as for table 2 except + , right atrial to pulmonary artery obstruction; 0 , no obstruction.

operated on for SV died with early arrhythmias as compared with $11 \%$ in the TA group ( $p=$ 0.033). Complete atrioventricular block appeared in two patients with TA and was well tolerated; both had permanent epicardial pacing systems implanted later. An early arrhythmia was documented in the patient with pulmonary atresia (atrial flutter) and the patient with double outlet right ventricle (atrial flutter).

When the preoperative variables of patients with early postoperative arrhythmias were compared with patients without arrhythmias, there were no significant differences in age (mean 12.2 (7.3) v 13.2(6.9) years), right atrial pressure (mean $6.0(2.9)$ v $5.9(2.1) \mathrm{mm} \mathrm{Hg}$ ), pulmonary artery pressure (mean $12.6(4 \cdot 4) v$ $15.4(5.6) \mathrm{mm} \mathrm{Hg}$ ), previous shunt duration (mean $11.7(4.8) v 10.9$ (3.9) years), ventricular function, or the presence of atrioventricular valve dysfunction.

Although not reaching statistical significance, there was a trend to higher right atrial pressures in the first 24 hours after operation in those patients with early postoperative atrial fibrillation (mean $16.7(2.9) \mathrm{mm} \mathrm{Hg}$ ) than in those either with or without other arrhythmias (15.4 (3.4) $\mathrm{mm} \mathrm{Hg}$ and 14.2 (3.1) $\mathrm{mm} \mathrm{Hg}$ respectively.

Preoperative characteristics in the group

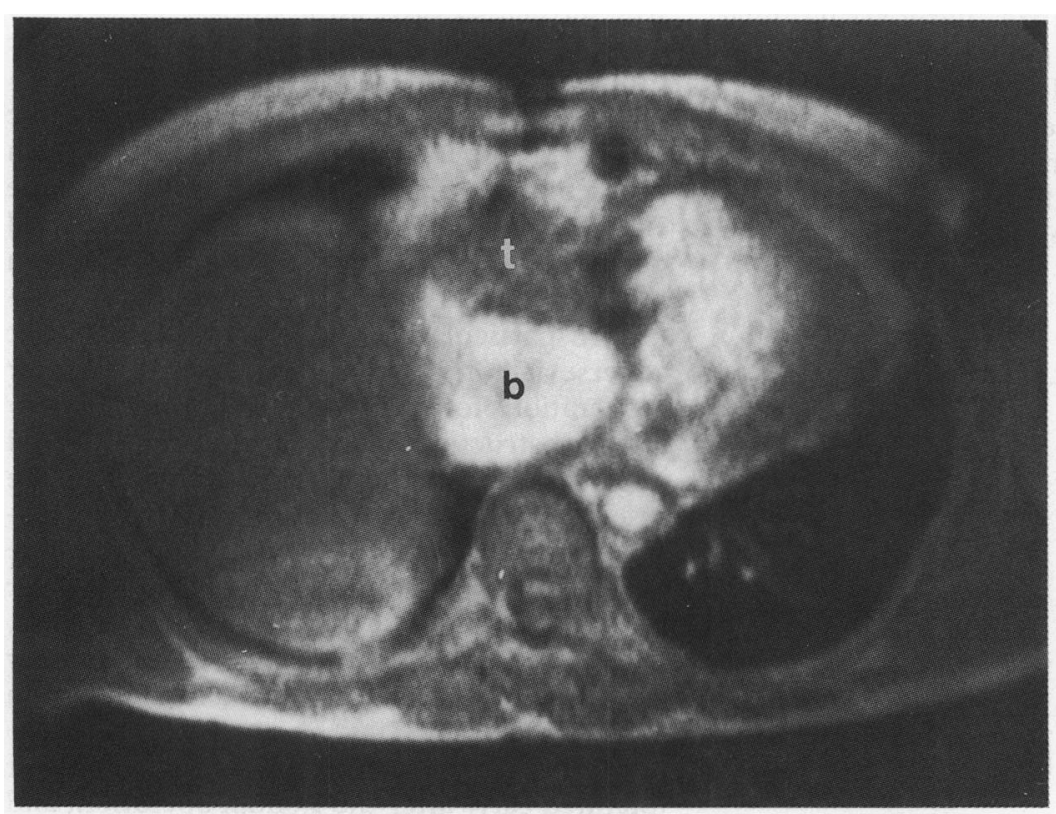

Figure 2 Magnetic resonance gradient echo image in the transverse thoracic plane (caudocranial view) at the level of the mid right atrium in end systole. This image shows blood (b) as a strong signal (white) and thrombus ( $t$ ) as an attenuated signal (grey) black) in the right atrium. This thrombus was not seen on single plane angiography. with fatal early arrhythmia were not significantly different from those in the survivors of an early arrhythmia or in the non-arrhythmic group.

\section{LATE ARRHYTHMIAS}

Table 3 summarises arrhythmias and their outcome in the late postoperative period. Comparison of the preoperative variables in patients with and without late postoperative arrhythmias showed no significant differences in age at operation (mean $13.7(6.0) v 13.2$ (6.9) years), underlying anomaly, presence of preoperative arrhythmia, right atrial pressures (mean 6.8 $(2 \cdot 8)$ v $5.9(2 \cdot 1) \mathrm{mm} \mathrm{Hg})$, pulmonary artery pressures (mean 12.8 (4.2) v $15.4 \quad(5.6)$ $\mathrm{mm} \mathrm{Hg}$ ), previous shunt surgery, and ventricular or AV valve function. There were no apparent preoperative determinants of those who were to develop rhythm disturbances late after the first Fontan procedure.

At cardiac catheterisation, however, between one and eight years after the Fontan procedure, pressures were higher in patients who subsequently developed arrhythmias than those who did not, in both the right atrium (16.6 (4.9) $v 11.3(3.1) \mathrm{mm} \mathrm{Hg}) ; \mathrm{p}=0.008)$ and pulmonary artery $(12.4(2.5) v 8.9(3.1) \mathrm{mm} \mathrm{Hg} ; \mathrm{p}=$ $0.013)$. The seven patients who developed atrial fibrillation and flutter tended to have the highest right atrial pressures (mean 17.5 $\mathrm{mm} \mathrm{Hg}$ ) before the start of the arrhythmia and after restoration of sinus rhythm, and six of these patients had a gradient between the right atrium and pulmonary artery of $5 \mathrm{~mm} \mathrm{Hg}$ or more, confirming significant obstruction to right atrial outflow that was clinically apparent in only two cases. Patients who developed late arrhythmias after the Fontan procedure had significantly higher mean right atrial pressure as early as 24 hours after the procedure than those who did not (mean 18.2 (3.3) v 14.5 (3.7) $\mathrm{mm} \mathrm{Hg} ; \mathrm{p}=0.010$ ).

Ventricular function (as determined by radionuclide ejection fraction), of patients when in sinus rhythm within two months of the onset of an arrhythmia was worse than in nonarrhythmic patients (mean ejection fraction $35 \%(11.9 \%)$ v $45 \%(10.4 \%) ; p=0.034)$, measured in both groups at a mean of five years after the Fontan procedure. The mean preoperative ejection fraction for both these groups was $52 \%(11.5 \%)$.

Of the 15 patients with late arrhythmias two (sinus bradycardia with atrioventricular nodal escape rhythm one, atrial fibrillation one) were asymptomatic, nine (atrial flutter four, atrial fibrillation two, AV reentrant tachycardia two, 
Table 4 Early arrhythmias after reoperation (in nine of 18 patients)

\begin{tabular}{|c|c|c|c|c|c|c|c|c|c|}
\hline \multirow[b]{3}{*}{$\begin{array}{l}\text { Previous arrhythmia } \\
\text { Age at reoperation }(y r) \\
\text { RA-PA obstruction } \\
\text { Fatal }\end{array}$} & \multicolumn{9}{|l|}{ Rhythm } \\
\hline & \multirow{2}{*}{$\begin{array}{l}\begin{array}{l}N R \\
(n=1)\end{array} \\
\text { AF } \\
28 \\
+ \\
0\end{array}$} & \multicolumn{3}{|c|}{$\begin{array}{l}A F \\
(n=3)\end{array}$} & \multicolumn{2}{|c|}{$\begin{array}{l}\text { AFlut } \\
(n=2)\end{array}$} & $\begin{array}{l}\begin{array}{l}S V T \\
(n=1)\end{array} \\
-\end{array}$ & $\begin{array}{l}V T \\
(n=1)\end{array}$ & $\begin{array}{l}\text { New } C H B \\
(n=1)\end{array}$ \\
\hline & & $\begin{array}{l}\overline{12} \\
+ \\
+\end{array}$ & $\begin{array}{l}\text { AF } \\
22 \\
+ \\
+\end{array}$ & $\begin{array}{l}\text { AF } \\
17 \\
+ \\
+\end{array}$ & $\begin{array}{l}\text { AF1 } \\
9 \\
0 \\
0\end{array}$ & $\begin{array}{l}- \\
25 \\
+ \\
+\end{array}$ & $\begin{array}{l}- \\
23 \\
+ \\
+\end{array}$ & $\begin{array}{l}\overline{13} \\
+ \\
+\end{array}$ & $\begin{array}{l}\overline{12} \\
+ \\
+\end{array}$ \\
\hline
\end{tabular}

Footnotes as for tables 2 and 3 as appropriate.

ventricular tachycardia one) experienced associated palpitation, two (atrial fibrillation one, ventricular tachycardia one) had anginalike chest pain, one (atrial flutter) had syncope, and one (atrial flutter) had haemodynamic collapse. After the onset of an arrhythmia exercise tolerance and ability index (as defined by Warnes and Somerville ${ }^{3}$ ) were reduced. The reduction persisted even after restoration of stable sinus rhythm. After the onset of arrhythmia, investigation showed a new thrombus in the right atrium in two patients and pulmonary embolism was suspected in two more; this was confirmed by perfusion scanning in one. All four of these patients had atrial fibrillation or flutter. A large right atrial thrombus that was missed at angiography was clearly shown on magnetic resonance imaging in one case (fig 2). Of the five late sudden deaths in this series, data from necropsy exists in three patients, showing pulmonary embolism in one and right atrial thrombus in another. Survivors of early postoperative arrhythmias were no more likely to develop late arrhythmias than patients who had no early arrhythmias.

\section{REOPERATION}

Reoperation for right atrium to pulmonary artery obstruction was carried out in 18 patients in this series, three months to 14 (mean $6 \cdot 8(3 \cdot 7)$ ) years after the first Fontan procedure. Of these, 15 had obstruction of right atrium to pulmonary artery flow with a gradient of at least 5 (mean $7.6(2 \cdot 4)) \mathrm{mm} \mathrm{Hg}$. Early arrhythmias occurred after reoperation in nine $(50 \%)$ of the reoperated patients. Three of these patients had atrial fibrillation early after reoperation, again with fatal outcome. Two of these three patients had had atrial fibrillation late after the original procedure (table 4).

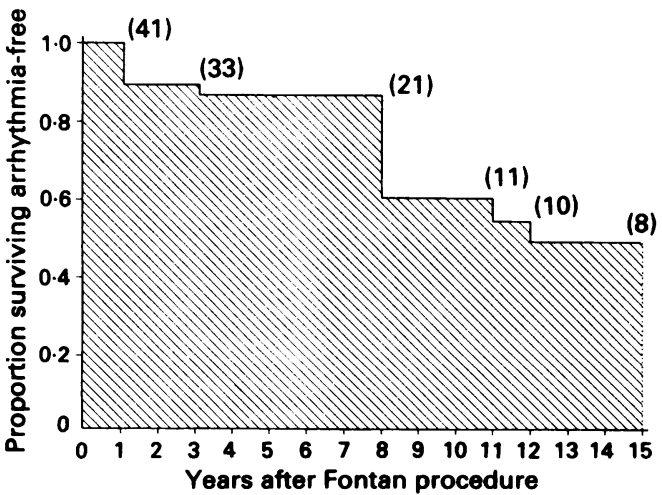

Figure 3 Arrhythmia free survival of the 41 hospital survivors of the Fontan procedure 1972-1986. This figure shows a probability of arrhythmia free survival of $60 \%$ at 10 years (11 patients) and $50 \%$ at 15 years (eight patients).
Figure 3 shows the actuarial arrhythmia free survival (AFS) curve for hospital survivors of the Fontan procedure (41 patients). Eleven patients remain free of arrhythmia at 10 yearsan actuarial 10 year AFS of $60 \%$. Eight patients remain free of arrhythmia at 15 years-an actuarial 15 year AFS of $50 \%$.

\section{Discussion}

The long follow up in this series includes the pioneering experience of the Fontan procedure, with inevitable errors in patient selection as well as operative technique reflected in the higher mortality and morbidity before 1980.

The incidence of early postoperative arrhythmias was $32 \%$ (19/60 patients) with a fatal outcome in $58 \%$ (11/19 patients)

Atrial fibrillation occurred in the early postoperative period in $10 \%$ of patients, and was fatal in all cases probably because the importance of unfavourable factors which lead to a higher postoperative right atrial pressure had been underestimated. Atrial fibrillation was more common in double inlet ventricle than in tricuspid atresia even though age and preoperative pulmonary artery pressures were similar in the two groups. This probably relates to the more extensive atrial surgery in double inlet ventricle and a tendency to underestimate the degree of pulmonary vascular disease.

There was a trend to higher immediate postoperative right atrial pressures in those who developed early atrial fibrillation and this may reflect an underlying haemodynamic problem that worsened with the arrhythmia.

Preoperative atrial fibrillation recurred in the early postoperative period. With such problems resulting from atrial fibrillation in the early postoperative period, we now regard documented preoperative atrial fibrillation as a relative contraindication to the Fontan procedure particularly in the presence of other adverse factors. Atrial fibrillation early after reoperation for right atrium to pulmonary artery obstruction was also associated with fatal outcome and should therefore influence the assessment of reoperative risk. If atrial fibrillation does occur in the early postoperative period it requires immediate conversion rather than only attempts to slow the ventricular rate. The newer technique of total cavopulmonary anastomosis may avoid such difficulties with atrial fibrillation. ${ }^{4}$

Atrial flutter, by contrast, was better tolerated early after the Fontan operation, and easily reverted to sinus rhythm, either spontaneously or by early DC countershock. His bundle tachycardia occurred in only two and was fatal because it could not be slowed or 
terminated; this arrhythmia was not encountered after reoperation.

The data relating to early postoperative arrhythmias in this series contrast with two recent studies; Kurer et al reported early postoperative arrhythmias in $31(93 \%)$ of 33 patients of mean age 4.6 years, but death occurred in only three $(10 \%))^{5}$ Gewillig et al reported a series of mean age $7 \cdot 1$ years, in which $11(9 \%)$ of 104 patients developed early arrhythmias, and $10(90 \%)$ died. ${ }^{6}$ The great variation in reported figures for both incidence and resulting mortality may arise from the difference in age of the populations, which was considerably greater in our series (mean 12.3 years), different surgical techniques, and an apparent absence of atrial fibrillation in the entire period of postoperative study in the other series. Recent reports of the experience of the Mayo Clinic show hospital mortality $(8 \%$ and $11.7 \%$ ) after Fontan operations performed in the 1980 s resembling that in our series $(10 \%)$, but give little specific information about arrhythmia. $^{78}$

Atrioventricular junctional rhythms and complete atrioventricular block were both well tolerated early and late after construction of the Fontan circulation, which clearly is not critically dependent on the coordinated atrial transport of sinus rhythm.

The onset of late atrial arrhythmias after the Fontan procedure was related to raised right atrial pressure as measured both early and late after the surgery. Atrial arrhythmias were often the first manifestation of significant right atrial to pulmonary artery obstruction. Higher right atrial pressures after the Fontan procedure may be caused by pulmonary vascular disease, obstruction to right atrial outflow, or impaired ventricular function. Finding higher right atrial pressures as early as 24 hours after surgery in the group that subsequently developed arrhythmias may be explained by any of these mechanisms. In some cases obstruction and an excessive pulmonary vascular resistance were excluded at cardiac catheterisation, suggesting impairment of ventricular function as a cause.

By contrast with the series from Weber $e t a l^{9}$ early postoperative arrhythmias did not predict the occurrence of late arrhythmia. Right atrial thrombus with or without pulmonary embolism was associated with the onset of late atrial fibrillation and flutter. Deteriorating right atrial function and flow from increasing obstruction before the start of the arrhythmia is probably the cause, but the precise mechanism cannot be determined with certainty.

Conventional transthoracic echocardiography should be useful in the detection of right atrial obstruction and intracardiac thrombus but often a poor echocardiographic window makes it difficult to image the anteriorly placed conduit particularly in older patients. Transoesophageal echocardiography (TOE) is reliable for the detection of obstruction ${ }^{10}$ as is magnetic resonance imaging (MRI) with flow studies, ${ }^{11}$ although problems with $R$ wave gating may make it difficult to acquire clear images with MRI if the patient is in atrial fibrillation. Either TOE or MRI (or both) should be performed regularly in the follow up of any Fontan patient, particularly when arrhythmias occur. Early recognition of obstruction is essential if atrial and ventricular function are to be restored or maintained; arrhythmias may be a late (but still the first) clinical manifestation of such obstruction, which may go unrecognised for a long period. Arrthythmias also occur without obstruction but, whether or not there is obstruction, anticoagulation should be considered in view of the risk of right atrial thrombus.

The continued deterioration in ventricular function and symptoms after reversion to sinus rhythm suggests that such deterioration is related to the cause rather than to the effect of the arrhythmia. The decline in ventricular function was similar in patients with ventricular and supraventricular arrhythmias-so the mechanism of arrhythmogenesis in those with supraventricular arrhythmia may therefore have involved left atrial distension secondary to a rising ventricular end diastolic pressure and mitral regurgitation in some cases. It is tempting, however, to suggest that the apparent deterioration in ventricular function, often with a normal sized systemic ventricle, in this group of patients may be a result of impaired filling from obstructed pulmonary flow at the right atrial to pulmonary artery connection, leading to progressive diastolic ventricular dysfunction. Filling characteristics are an important determinant of ventricular function. In the context of the Fontan circulation, in which the precise mechanism of pulmonary flow has never been conclusively determined, conventional methods of assessment of the function of the ventricle in the presence of restricted inflow characteristics may be misleading. Perhaps this explains the poor outcome after surgical relief of chronic right atrium to pulmonary artery obstruction, with a systemic ventricle now unable to cope with restoration of normal flow. Certainly the importance of early diagnosis and relief of obstruction, with or without arrhythmias, cannot be overemphasised.

To date it must be concluded that with the Fontan circulation the start of arrhythmias, particularly atrial, signal a deterioration in function and must stimulate an early search for a remediable cause. Treatment of the arrhythmia alone is inadequate and if right atrial to pulmonary artery obstruction remains unrecognised it may result in irreversible cardiac dysfunction.

We thank Mr Donald Ross and Professor Sir Magdi Yacoub who performed most of the surgical procedures, Susan Stone for her help in compiling the data referred to in this study, and Simon Rees and Philip Kilner for their magnetic resonance expertise.

1 Fontan F, Baudet E. Surgical repair of tricuspid atresia. Thorax 1971;26:240-8.

2 Gale AW, Danielson GK, McGoon DC, Mair DD. Modified Fontan operation for univentricular heart and complicated congenital lesions. J Thorac Cardiovasc Surg 1979;78:831-8.

3 Warnes CA, Somerville J. Tricuspid atresia in adolescents and adults: current state and late complications. $\mathrm{Br}$ Heart $J$ 1986;56:535-43. 
4 DeLeval MR, Kilner P, Gewellig M, Bull C, McGoon DC. Total cavopulmonary connection: a logical alternative to atriopulmonary connection for complex Fontan operations. J Thorac Cardiovasc Surg 1988;96:682-95.

5 Kurer CC, Tanner CS, Norwood WI, Vetter VL. Perioperative arrhythmias after Fontan repair. Circulation 1990;82(suppl IV):190-4.

6 Gewellig M, Lundstrom U, Wyse D, Deanfield J. Determinants and outcome of early and late arrhythmia after Fontan operation. J Am Coll Cardiol 1989;13:170.

7 Mair DD, Hagler DJ, Puga FJ, Schaff HV, Danielson GK. Fontan operation in 176 patients with tricuspid atresia. Fontan operation in 176 patients with tricuspid atresia. Circulation 1990;82(suppl IV):164-9.

8 Danielson GK, Puga FJ, Schaff HV. Surgical treatment of complex congenital heart disease with modified Fontan procedure. Journal of the Japanese Association for Thoracic Surgery 1989;37:831-6.

9 Weber HS, Hellebrand WE, Kleinman CS, Perlmutter RA Rosenfeld LE. Predictors of rhythm disturbances an subsequent morbidity after the Fontan operation. Am Cardiol 1989;64:762-7.

10 Stumper O, Sutherland GR, Geuskens R, Roelandt JR, Bos E, Hess $\mathrm{J}$. Transesophageal echocardiography in evaluation and management after a Fontan procedure. J Am Coll
Cardiol 1991;17:1152-60.

11 Sampson C, Martinez J, Rees S, Somerville J, Underwood R, Longmore D. Evaluation of Fontan's operation by magnetic resonance imaging. Am J Cardiol 1990;65: magnetic 